\title{
Mechanism of SEMA3G knockdown-mediated attenuation of high-fat diet-induced obesity
}

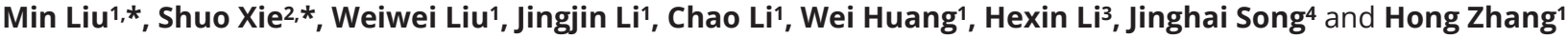 \\ ${ }^{1}$ Institute of Cardiovascular Sciences and Key Laboratory of Molecular Cardiovascular Sciences, Peking University Health Science Center, Beijing, China \\ 2Department of Geriatric Medicine, Peking University First Hospital, Beijing, China \\ ${ }^{3}$ Biological Sample Management Center, Beijing Hospital, Beijing, China \\ ${ }^{4}$ Department of Surgery, Beijing Hospital, Beijing, China
}

Correspondence should be addressed to H Zhang: zhanghong@bjmu.edu.cn

*(M Liu and S Xie contributed equally to this work)

\begin{abstract}
Obesity is a worldwide health problem. Semaphorins are involved in axonal guidance; however, the role of secretory semaphorin 3G (SEMA3G) in regulating adipocyte differentiation remains unclear. Microarray analysis showed that the SEMA3G gene was upregulated in an in vitro model of adipogenesis. In this study, SEMA3G was highly expressed in the white adipose tissue and liver. Analysis of 3T3-L1 cell and primary mouse preadipocyte differentiation showed that SEMA3G mRNA and protein levels were increased during the middle stage of cell development. In vitro experiments also showed that adipocyte differentiation was promoted by SEMA3G; however, SEMA3G inhibition using a recombinant lentiviral vector expressing a specific shRNA showed the opposite results. Mice were fed a chow or high-fat diet (HFD); knockdown of SEMA3G was found to inhibit weight gain, reduce fat mass in the tissues, prevent lipogenesis in the liver tissue, reduce insulin resistance and ameliorate glucose tolerance in HFD mice. Additionally, the effect of SEMA3G on HFD-induced obesity was activated through PI3K/Akt/GSK3 $\beta$ signaling in the adipose tissue and the AMPK/SREBP-1c pathway in the liver. Moreover, the plasma concentrations of SEMA3G and leptin were measured in 20 obese and 20 non-obese human subjects. Both proteins were increased in obese subjects, who also exhibited a lower level of adiponectin and presented with insulin resistance. In summary, we demonstrated that SEMA3G is an adipokine essential for adipogenesis, lipogenesis, and insulin resistance and is associated with obesity. SEMA3G inhibition may, therefore, be useful for treating diet-induced obesity and its complications.
\end{abstract}
Key Words
- semaphorin
- adipokine
- obesity
- adipogenesis
- lipogenesis

\section{Introduction}

Obesity is a major health problem worldwide. The morbidity of overweight conditions and obesity has more than doubled since 1980 and was reported to be $5 \%$ in children and $12 \%$ in adults in 2017. Epidemiological evidence links obesity to numerous complications, such as type 2 diabetes, exhibiting similar global trends, fatty liver diseases including cholelithiasis and dyslipidemia, cardiovascular and cerebrovascular disease, as well as various cancers and, therefore, may substantially contribute to shortened lifespans. These findings emphasize the urgency of gaining an in-depth understanding of obesity (Cabia et al. 2016, Gregg \& Shaw 2017, Khemka \& Banerjee 2017). 
Animal liver and adipose tissue are the main sites of lipogenesis and adipogenesis (Musso et al. 2013). Adipose tissue includes adipocytes and a stromal-vascular fraction comprising preadipocytes, fibroblasts, endothelial cells, macrophages, and other immune cells. There are generally two types of adipose tissue based on structural and functional differences in the adipocytes: white adipose tissue (WAT) and brown adipose tissue (BAT) (Marta \& Francesc 2013). The two types of adipocytes are derived from different precursor cells and have distinct morphological features. Mesenchymal precursor cells can produce white adipocytes, acting as a store of energy in the form of lipids, under conditions of excess calories, while Myf5-expressing precursor cells yield brown adipocytes, which are major site of non-shivering thermogenesis and function as a source of calories during periods of fasting in mammals (Giralt \& Villarroya 2013). Obesity is excessive accumulation of WAT (Sarjeant \& Stephens 2012). WAT is distributed beneath the skin and around the abdominal organs and plays a very significant endocrine role, secreting numerous molecules including metabolites, lipids, and bioactive peptides known as 'adipokines', which exert regulatory functions. Adipose tissue dysfunction leads to deregulation of adipokine secretion, thus contributing to obesity (Fasshauer \& Bluher 2015). Adiponectin and leptin are two major adipokines involved in regulating body fat homeostasis and insulin sensitivity (Kadowaki et al. 2006, Rosenbaum \& Leibel 2014).

Two decades of research on the differentiation of preadipocytes to adipocytes has shown that the process is regulated by a complex network of transcription factors (Kuri-Harcuch et al. 2019). Particularly, peroxisome proliferator-activated receptor gamma (PPAR $\gamma)$ is considered as the most critical regulator of adipogenesis, as most genes specific to differentiated adipocytes are direct targets of PPAR $\gamma$ (Lefterova et al. 2014). PPAR $\gamma$ can alter the phosphorylation level of phosphoinositide 3-kinase (PI3K) and protein kinase B (Akt) in type 2 diabetic mice (Wang et al. 2016) and in mice with radiationinduced fibrosis (Vallée et al. 2017). In obese and diabetic individuals, signaling by PI3K/Akt, AMP-activated protein kinase (AMPK), and mitogen-activated protein kinases is deregulated (Schultze et al. 2012). AMPK is considered as a promising therapeutic target for obesity. In the liver, AMPK phosphorylation leads to decreased levels of sterol regulatory element-binding protein-1c (SREBP-1c) and fatty acid synthetase (FAS) and the phosphorylation of acetyl coenzyme A carboxylase 1 (Ok et al. 2013, Dihingia et al. 2018, Li et al. 2018).
Notably, SEMA3 proteins (SEMA3A-G) are secreted proteins that function similar to other members of the family (Serini et al. 2013, Valdembri et al. 2016). Most membrane-bound SEMA bind to plexins, and SEMA3s bind neuropilins (Nrps) as obligate co-receptors (Pasterkamp 2012). SEMA3s exert their signaling functions through holoreceptor complexes composed of Nrps, proteoglycans, and/or plexins (Bussolino et al. 2014).

SEMA3G was cloned in 2005 and predicted to be a chemorepulsive protein in sympathetic axons (Taniguchi et al. 2005). Several studies revealed that SEMA3G strongly binds to Nrp2 and activates the related downstream pathway, but binds weakly to Nrp1 (Kutschera et al. 2010, Liu et al. 2015, Ishibashi et al. 2016). We reported that SEMA3G is the target gene of PPAR $\gamma$ in human umbilical vein endothelial cells and induces Rac1-dependent lamellipodia formation (Liu et al. 2015). Induction of adipogenesis in 3T3-L1 cells was observed in microarray analysis and was accompanied by upregulation of 918 genes and downregulation of 20 genes. Among these genes, 43 exhibited a transcriptional peak at $6 \mathrm{~h}$ after stimulation of adipogenesis; among these genes SEMA3G displayed over four-fold increased expression during adipogenesis (Fromm-Dornieden et al. 2012). Although SEMA3G mRNA is present in different tissues, bioinformatics analysis revealed that it is most abundant in adipose tissue, followed by endothelial cells and hepatocytes (https:// www.proteinatlas.org/ENSG00000010319-SEMA3G/cell). Therefore, whether SEMA3G is involved in adipogenesis should be further examined.

In this study, we evaluated the role of the new adipokine SEMA3G in adipocyte differentiation, lipogenesis, and insulin resistance.

\section{Materials and methods}

\section{Cell culture}

3T3-L1 cells were grown in six-well plates in Dulbecco's modified Eagle's medium (DMEM, Invitrogen) containing $10 \%$ fetal bovine serum (FBS) at $37^{\circ} \mathrm{C}$ in $5 \% \mathrm{CO}_{2}$. Confluent 3T3-L1 cells were stimulated to differentiate in DMEM containing $10 \%$ FBS, $1 \mu \mathrm{M}$ dexamethasone, $0.5 \mathrm{mM}$ isobutylmethylxanthine, and $5 \mu \mathrm{g} / \mathrm{mL}$ insulin for 2 days, followed by treatment with $5 \mu \mathrm{g} / \mathrm{mL}$ insulin alone. The medium was changed every 2 days.

Mouse epididymal preadipocytes were isolated as previously described (Poulos et al. 2010). Epididymal fat 
pads from C57 mice were excised and separated from blood vessels and connective tissue. The fat pads were minced and incubated in DMEM supplemented with $0.8 \mathrm{mg} / \mathrm{mL}$ collagenase (Sigma) for $60 \mathrm{~min}$ under shaking. The collagenase digest was filtered through a $100-\mu \mathrm{M}$ screen and centrifuged at $36 \boldsymbol{g}$ for $20 \mathrm{~min}$. The pellet containing preadipocytes was resuspended in basal medium (DMEM/Ham's F12 (1:1 vol/vol)) containing $10 \%$ FBS. After $48 \mathrm{~h}$ of culture, the medium was changed to basal medium supplemented with $1 \mu \mathrm{M}$ dexamethasone, $0.5 \mathrm{mM}$ isobutylmethylxanthine, $5 \mu \mathrm{g} / \mathrm{mL}$ insulin, and $60 \mu \mathrm{M}$ indomethacin. The medium in the cell culture plates was replaced with basal medium and was changed every other day.

\section{Experimental animals}

Animals were maintained in a specific pathogen-free, temperature-controlled $\left(22 \pm 1^{\circ} \mathrm{C}\right)$ mouse facility on a reverse 12-h light/12-h darkness cycle at the Institute of Cardiovascular Sciences and Key Laboratory of Molecular Cardiovascular Sciences. All studied mice were on the C57BL/6 (4 weeks old) background, with an equal number of males and females and were fed either with food pellets containing 60\% kcal fat (D12492; Research Diets) or a regular chow diet for 21 weeks. All animal experimental protocols were approved by the Institutional Animal Care Research Advisory Committee of the National Institute of Biologic Science and the Animal Care Committee of Peking University Health Science Center (Permit Number: LA201058). Animals were allowed free access to tap water and maintained on a 12-h light/12-h darkness cycle. The experiments were performed in strict accordance with the principles of laboratory animal care (U.S. National Institutes of Health publication 85-23, revised 1985; http://grants1. nih.gov/grants/olaw/references/phspol.htm).

\section{RNA analysis and RT-PCR}

RNA was extracted from cultured cells and tissues using TRIzol (Invitrogen) reagent. Briefly, the cells and tissues were harvested in $1 \mathrm{~mL}$ of TRIzol, and $0.2 \mathrm{~mL}$ chloroform was added to the solution. RNA was precipitated with a 0.5 volume of isopropanol, washed with $70 \%$ ethanol, and air-dried. RNA pellets were dissolved in RNase-free water. Total RNA was reverse-transcribed with an iScript cDNA synthesis kit (Bio-Rad). Semi-quantitative reversetranscription polymerase chain reaction (RT-PCR) using specific primers for the SEMA3G and GAPDH genes was performed on an Opticon continuous fluorescence detection system (MJ Research, Waltham, MA, USA) using SYBR green (Molecular Probes). The primer sequences for SEMA3A-G and GAPDH are shown in Table 1. Gene expression was quantified using the comparative CT method, normalized to the expression of GAPDH, and expressed as fold-induction compared to the expression in the control.

\section{Protein analysis}

Cells and tissues were washed twice with ice cold $1 \times$ phosphate-buffered saline (PBS) and harvested in lysis buffer (1\% SDS, $100 \mathrm{mM} \mathrm{NaCl}, 50 \mathrm{mM}$ Tris-HCl (pH 8.0), and $20 \mathrm{mM}$ EDTA). The harvested cells were sonicated and centrifuged at $1613 \boldsymbol{g}$ for $20 \mathrm{~min}$ at $4^{\circ} \mathrm{C}$. After centrifugation, the supernatants were boiled for 5 min, separated on a $12 \%$ SDS-PAGE gel, and electroblotted onto nitrocellulose membranes. Blots were incubated overnight with antibodies against SEMA3G, $\beta$-actin (Sigma-Aldrich), P-PI3K, PI3K, P-Akt, Akt, P-GSK3 $\beta$, GSK3 $\beta$, SREBP-1c, P-AMPK, AMPK, SREBP-1c, FAS, P-ACC, and ACC (Table 2) followed by incubation for $1 \mathrm{~h}$ at room temperature with a horseradish peroxidase-linked secondary antibody (Santa Cruz Biotechnology). Blots were visualized with an enhanced chemiluminescence detection system (Pierce ECL) using an anti-rabbit or anti-mouse horseradish peroxidase antibody.

\section{Biochemical and hormonal determinations}

The serum and liver levels of triglyceride, cholesterol, and glucose (Millipore) and plasma levels of SEMA3G (Mybiosource, San Diego, CA, USA), adiponectin, and leptin (Linco Research, San Carlos, CA, USA) in mice were measured in duplicate using ELISA kits according to the manufacturer's instructions. All experiments were repeated at least three times.

After 21 weeks of high-fat-diet (HFD) and chow-diet feeding, mice aged 25 weeks were fasted from food for $6 \mathrm{~h}$ and then provided an oral gavage of glucose $(2 \mathrm{~g} / \mathrm{kg}$ body weight, i.p.; Abbott Laboratories) for the GLU tolerance test (GTT) or insulin $(0.75 \mathrm{mIU} / \mathrm{g}$ body weight, i.p.; Humulin; Eli Lilly) for the insulin tolerance test (ITT). Blood samples from mice were assessed before (time 0 ) and at $15,30,60,90$, and $120 \mathrm{~min}$ after glucose administration for GLU measurement. 
Table 1 Primer sequences for SEMA3A-G, GAPDH, ADIPOQ, PPAR- $\gamma$, CEBP- $\alpha$ and FABP4.

\begin{tabular}{l}
\hline Gene \\
\hline SEMA3A \\
SEMA3B \\
SEMA3C \\
SEMA3D \\
SEMA3E \\
SEMA3F \\
SEMA3G \\
GAPDH \\
ADIPOQ \\
PPAR- $\gamma$ \\
CEBP- $\alpha$ \\
FABP4
\end{tabular}

\begin{tabular}{ll}
\hline \multicolumn{1}{c}{ Primer sequences } \\
\hline Forward $\left(5^{\prime}-3^{\prime}\right)$ & Reverse $\left(5^{\prime}-3^{\prime}\right)$ \\
\hline CTCTCCTCTCCCATTGTCAG & CCGGTGGCTGACTCTAATCC \\
GAAGGCCTCTGATAGTCCGC & GGGAAACCTGACTCTAATCC \\
GCGTTATTCCCGTGCATGTC & TGGGGTTCTGTCCATGATGC \\
TTGGAACGAGTCAGTGACGG & ATGGCGTCATCGGGGTAATC \\
CTGATGCGCGTTGTCATCTG & GAGAAGGTTCTGCCTCACCC \\
ATCTGTCTCCATGCTTTGGAAT & GGCTCCTGAACCAACTAATGTC \\
ACCACAGTCCATGCCATCAC & ACCCTTGCATCCTTCACAAG \\
TACTGGGCCGACCAGATTCC & CCCGTGGGTTGGGATATAGTT \\
ACGAGAGTCAGCCTTAAAGA & GGAGATGCAGGCTCCACTTT \\
AAATGAGACTCTCCGTCGGC & AAGAGGGGCTCAGGATGGAT \\
ATGGGGGTGTCCTGGTACAT & ACGTCCCTTGGCTTATGCTC \\
\hline
\end{tabular}

\section{Immunohistochemistry}

Tissues were fixed in $4 \%$ paraformaldehyde and sliced. The tissue slices were permeabilized with $0.1 \%$ Triton and blocked with $3 \%$ bovine serum albumin. Tissue slices were incubated with an antibody against SEMA3G at $4^{\circ} \mathrm{C}$ overnight. After washing with PBS, the tissue slices were incubated with horseradish peroxidase-linked secondary antibody for $1 \mathrm{~h}$. The tissue slices were photographed under a light microscope.

\section{Oil Red O staining}

Oil Red O (Sigma) was dissolved in isopropanol. The cells were washed twice in PBS and fixed in $4 \%$ glutaraldehyde for $10 \mathrm{~min}$. After fixation, the cells were washed with PBS twice and incubated with Oil Red $\mathrm{O}$ solution for $10 \mathrm{~min}$. The cells were finally washed twice in PBS. Cells were photographed at $\times 40$ under a light microscope. Lipid accumulation was assessed by measuring the sample absorbance at OD490 in destained Oil Red O with isopropanol.

\section{Nile Red staining}

Primary mouse preadipocytes were washed with PBS twice and stained with Nile Red solution in PBS diluted to 1:1000 from the saturated solution in acetone for $10 \mathrm{~min}$ at room temperature. Lipid droplets were photographed under a fluorescence microscope.

\section{Adenovirus and lentivirus infection}

SEMA3G and GFP adenovirus infections were performed as described previously (Binxia et al. 2014). mSEMA3G shRNA containing lentiviral particles (LV-shSEMA3G,
sc-153332-V) for the in vivo and in vitro knockdown of the SEMA3G gene and a control shRNA (LV-shNC, sc-108080) were designed at Santa Cruz Biotechnology. 3T3-L1 cells and primary mouse preadipocytes were seeded at $8 \times 10^{8}$ cells per well in six-well plates. After overnight culture, supernatants containing lentivirus $\left(1 \times 10^{6} \mathrm{IFU} / \mathrm{mL}\right)$ were added to the wells in the presence of $5 \mu \mathrm{g} / \mathrm{mL}$ Polybrene according to the manufacturer's instructions. Fortyeight hours after infection, the differentiation of 3T3-L1 cells and primary mouse preadipocytes was stimulated through cocktail induction. Lentiviruses (LV-shSEMA3G) were injected into $\mathrm{C} 57 \mathrm{BL} / 6$ mice via the tail vein $(0.1 \mathrm{~mL}$ concentrated viral suspension with a viral titer of $5 \times 10^{6} \mathrm{IFU} / \mathrm{mL}$ in PBS); the same dose of LV-shNC was used as a control. We constructed an overexpression vector containing full-length SEMA3G in a lentivirus (LV-SEMA3G), and the doses used in animal experiments were the same as those described earlier.

\section{Patients}

Forty subjects (63-77 years old) with or without obesity were recruited and divided into four groups according to sex and somatotype at Beijing Hospital. Our study was carried out in accordance with The Code of Ethics of the World Medical Association (Declaration of Helsinki) for experiments involving humans. The study protocols were approved by the Ethical Review Board of Beijing Hospital. Written informed consent was obtained from all subjects.

Body weight and height were measured with the subject lightly clothed and bare footed using an electronic weighing scale (Tanita, Tokyo, Japan) and a Harpenden stadiometer. Obesity was defined as a body mass index greater than the 95th percentile. These percentile standards were established by a local population survey. 


\section{Blood sample collection and biochemical tests}

Venous blood samples were obtained in Vacuette tubes between 06:00 and 20:00 h after an overnight fast. After centrifuging at $1000 \mathrm{~g}$ for $15 \mathrm{~min}$ at $4^{\circ} \mathrm{C}$, serum samples were separated and stored at $-80^{\circ} \mathrm{C}$ until analysis. The serum levels of triglyceride, low-density lipoprotein-C, cholesterol, glucose, SEMA3G, adiponectin, and leptin were measured.

\section{Statistical analysis}

All numerical data are expressed as the mean \pm S.D. Statistical analysis was performed using two-way ANOVA followed by Tukey test for nonparametric data. The GraphPad Prism 6.0 software (GraphPad Software) was used for statistical analyses. The area under the curve (AUC) for glucose and insulin was calculated as described previously (Andrikopoulos et al. 2008, Liu et al. 2018). Statistical significance was defined as $P<0.05$.

\section{Results}

\section{SEMA3G expression in different tissues}

We measured the SEMA3G mRNA levels in different tissues and found that it was mainly expressed in the lung, liver, and WAT. As demonstrated previously, SEMA3G plays numerous roles in the lung (Ito et al. 2000, Kagoshima \& Ito 2001). Here, we mainly focused on SEMA3G functions in the inguinal WAT (iWAT), epididymal WAT (eWAT), and liver (Fig. 1A). Immunohistochemistry analysis showed that SEMA3G was mainly localized in the cytoplasm and intercellular substance in iWAT, eWAT, and liver and, to a lower extent, in the BAT (Fig. 1B). Because of the aggregation and distribution of SEMA3G in liver and adipose tissue, it is speculated that SEMA3G may play a specific role in these areas.

\section{SEMA3G expression was significantly increased during adipocyte differentiation}

We analyzed adipocyte differentiation of 3T3-L1 cells based on a 7-day test (Fig. 1C). At days 3 and 5, SEMA3G mRNA expression was increased by 5.5- and 5-fold, respectively, compared to that at day 0 , whereas no significant changes were detected at days 1 and 7. Similarly, the SEMA3G protein level was increased by 2 - and 3-fold at days 3 and 5 , respectively, while no significant changes were detected at days 1 and 7. Furthermore, we measured mRNA and protein levels in isolated preadipocytes from 
A

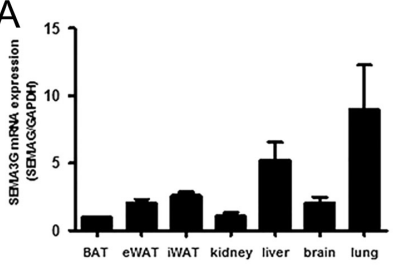

B

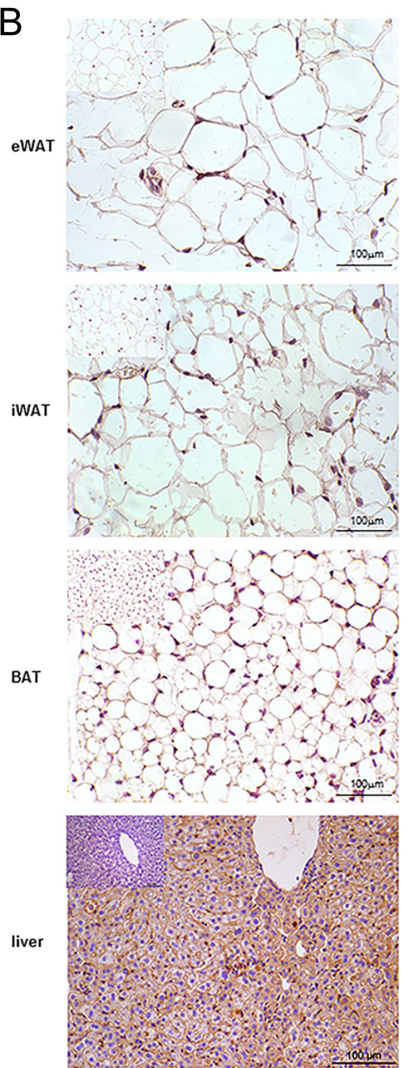

\section{Figure 1}

SEMA3G expression significantly increased during adipocyte differentiation (A). SEMA3G mRNA distribution in different tissues. (B) Hematoxylin and eosin staining in eWAT, iWAT, BAT and liver of C57BL/6 mice. Representative images are shown (200×). (C and D) SEMA3G mRNA and protein expression changes during adipocyte differentiation in 3T3-L1 cells and isolated preadipocytes of C57BL/6 mice. Data are expressed as mean \pm S.D. $* P<0.05 ; * * P<0.01 ; * \star * P<0.001$ vs day 0 . A full colour version of this figure is available at https://doi. org/10.1530/JOE-19-0029.

the mouse epididymis during in vitro differentiation and obtained similar results (Fig. 1D). Interestingly, the level of secretory SEMA3G in the supernatant of 3T3-L1 cells was increased by 2-, 2.5-, and 1.7-fold at days 3,5 , and 7 , respectively, whereas in mouse preadipocytes, it was increased by 3.6- ,5-, and 3-fold at days 3, 5, and 7, respectively (Supplementary Fig. 1A, see section on supplementary materials given at the end of this article). By conducting PCR for PPAR- $\gamma$, CEBP- $\alpha$, FABP4, and $\mathrm{ADIPOQ}$, which are specific markers of adipogenesis, we found that knockdown or overexpression of SEMA3G altered adipose differentiation. Knockdown led to delayed adipose differentiation, while overexpression promoted this process. The results were measured on days 3 and 5 (Supplementary Fig. 2A and B). These findings suggest an association between SEMA3G upregulation and adipocyte differentiation. Moreover, the increase in secretory SEMA3G may reflect its role as an adipokine.

\section{SEMA3G is essential for regulation of adipocyte differentiation}

To determine whether SEMA3G regulates adipocyte differentiation, we employed an adenovirus to overexpress SEMA3G (Ad-SEMA3G) in 3T3-L1 cells and used Ad-GFP as a control. Cells infected with Ad-SEMA3G exhibited a 13-fold increase in SEMA3G mRNA compared to Ad-GFPinfected cells (Fig. 2A), whereas the expression of SEMA3A-F remained unchanged (Supplementary Fig. 1B1). After 5-day Ad-SEMA3G infection, 3T3-L1 cell differentiation was significantly enhanced, as demonstrated by the 1.5fold increase in lipid accumulation compared to in the Ad-GFP control, as assessed by Red Oil O staining (Fig. 2B). Additionally, the mouse primary preadipocyte Ad-SEMA3G group showed seven-fold higher mRNA expression than the Ad-GFP cell group (Fig. 2C). Nile Red immunofluorescence and Red Oil $\mathrm{O}$ staining to detect lipid accumulation showed the same qualitative results (Fig. 2D). Neutralizing antibodies against Nrp2 effectively inhibited SEMA3G action on endothelial cell migration, as previously described. During the differentiation process, Ad-SEMA3G infection induced two-fold increased lipid accumulation in primary adipocytes, which was partly prevented by anti-Nrp2 antibodies (Supplementary Fig. 1C). This suggested that Nrp2-neutralizing antibodies can reverse the promoting action of SEMA3G on adipose differentiation, indicating that SEMA3G promotes adipocyte differentiation through the Nrp2 receptor.

To verify whether SEMA3G is essential for adipocyte differentiation, SEMA3G knockdown was confirmed by both RT-PCR and Western blot, showing a 50\% reduction in the mRNA level and 50\% decrease in the protein level in 3T3-L1 cells and primary mouse preadipocytes (Fig. 2E and $G$ ), whereas SEMA3A-F expression were unaffected (Supplementary Fig.1B2).Impairedadipocytedifferentiation as a result of SEMA3G knockdown was demonstrated by reduced lipid accumulation, detected in both types of adipocytes by Red Oil $\mathrm{O}$ staining and immunofluorescence (Fig. $2 \mathrm{~F}$ and $\mathrm{H}$ ). These data demonstrate that SEMA3G stimulated adipocyte differentiation. 
A

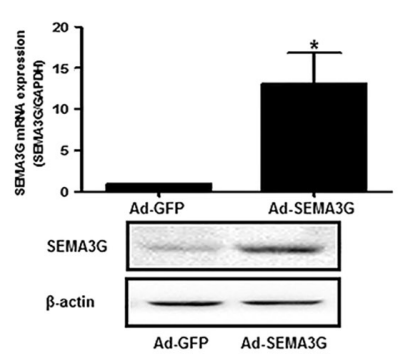

E

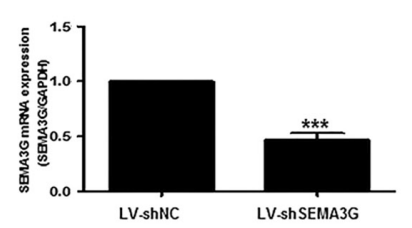

SEMA3G $\beta$-actin

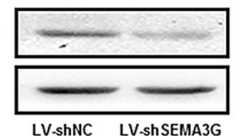

B

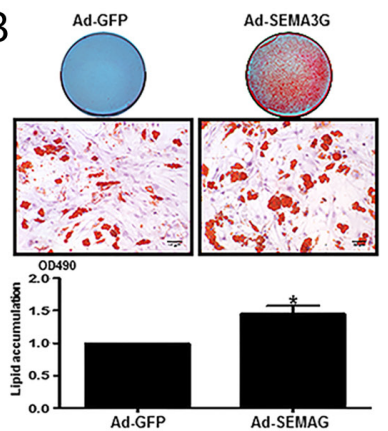

$\mathrm{F}$

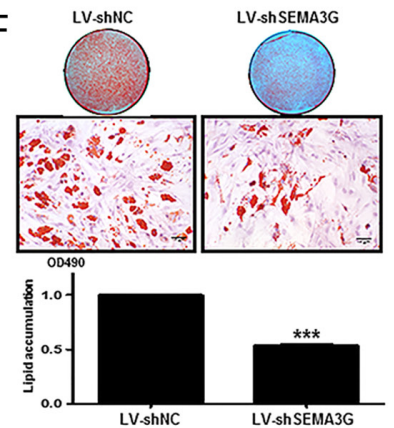

C

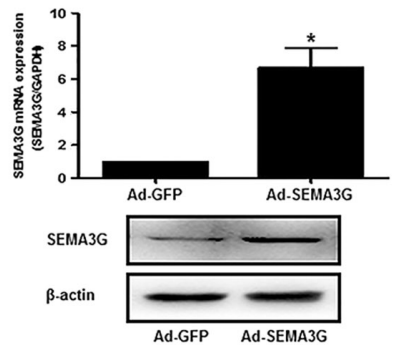

G

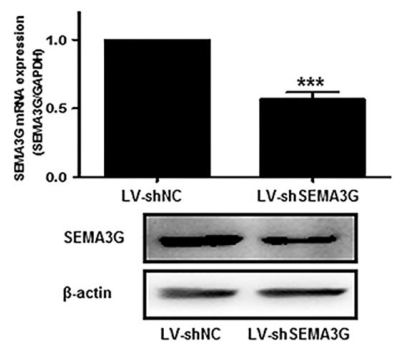

D

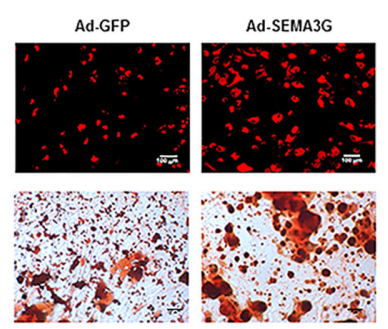

$\mathrm{H}$

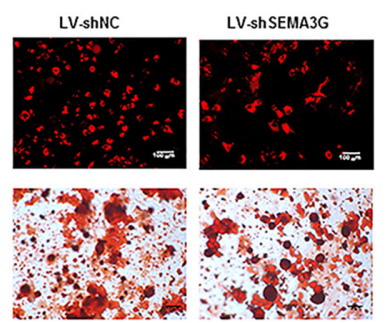

Figure 2

Effect of SEMA3G gain and loss function (A and C). SEMA3G mRNA and protein expression in Ad-GFP and Ad-SEMA3G group. (B) Oil Red O staining and lipid accumulation in livers of Ad-GFP and Ad-SEMA3G mice. (D) Nile Red immunofluorescent and Oil Red O staining of lipid accumulation in Ad-GFP and Ad-SEMA3G mice. Representative images are shown (200x). (E and G) SEMA3G mRNA and protein expression in LV-shNC and LV-shSEMA3G mice. (F) Oil Red $O$ staining in livers and lipid accumulation in LV-shNC and LV-shSEMA3G mice. Representative images are shown (200×). (H) Nile Red immunofluorescent and Oil Red O staining of lipid accumulation in LV-shNC and LV-shSEMA3G mice. Data are expressed as mean \pm S.D. $* P<0.05$; $\star \star P<0.01 ; * \star \star P<0.001$. A full colour version of this figure is available at https://doi.org/10.1530/JOE-19-0029.

\section{SEMA3G knockdown prevented increases in body weight in HFD-fed mice}

HFD feeding to 4-week-mice resulted in significantly increased body weight after 17 weeks compared to in the normal chow group, while gradually decreased from week 21 to 25 after injection of LV-shSEMA3G at week 21 compared to HFD-mice injected with shNC. At the end of the experiment, the body weight of HFD-LV-shSEMA3G mice was comparable to that of those in the two chow diet groups. However, the body weight rapidly increased in mice in the HFD-LV-shNC group. There was no difference in food intake between the four groups (Fig. 3A), suggesting that the weight gain in HFD-LV-shNC animals occurred because of differences in adipose metabolism rather than in mechanical intake. Serum levels of SEMA3G, adiponectin, and leptin were comparable in the four groups at week 4. After 17 weeks, the HFD-fed groups showed higher serum levels of SEMA3G and leptin and a lower level of adiponectin compared with the chow groups. On week 21, of LV-shNC and LV-shSEMA3G, only LV-shSEMA3G-injected mice exhibited a decrease in the level of SEMA3G, as assessed

(C) 2020 Society for Endocrinology Published by Bioscientifica Ltd. Printed in Great Britain by ELISA. In the HFD-LV-shSEMA3G group, SEMA3G was decreased to a level close to that of the chow-LV-shNC group. After injection of LV-shSEMA3G, increased serum adiponectin and decreased leptin were also observed in the chow-diet group, indicating that SEMA3G downregulation affected the basal levels of these proteins. Moreover, SEMA3G knockdown attenuated both the reduction in adiponectin and the rise in leptin induced by the HFD, as the levels of these proteins were close to those of chowLV-shNC mice (Fig. 3B). In chow diet-mice, LV-shSEMA3G injection caused a 50\% decrease in SEMA3G expression, in BAT, iWAT, eWAT, and liver. In HFD-LV-shNC mice, SEMA3G mRNA increased by 1.6, 3.4, 2.5, and 3.8 folds in BAT, iWAT, eWAT, and liver, respectively, compared to chow-LV-shNC. On the other hand, in adipose tissue (AT) and liver, SEMA3G mRNA decreased by approximately $50-70 \%$ in HFD-LV-shSEMA3G group compared to HFD-LV-shNC (Fig. 3C). Moreover, in the brain, lung and heart, SEMA3G mRNA decreased by approximately $50 \%$ in HFD-LV-shSEMA3G group compared to HFD-LV-shNC (Supplementary Fig. 2C). Body composition analysis demonstrated that the weight gain was equally accounted for by adipose tissue and fat 

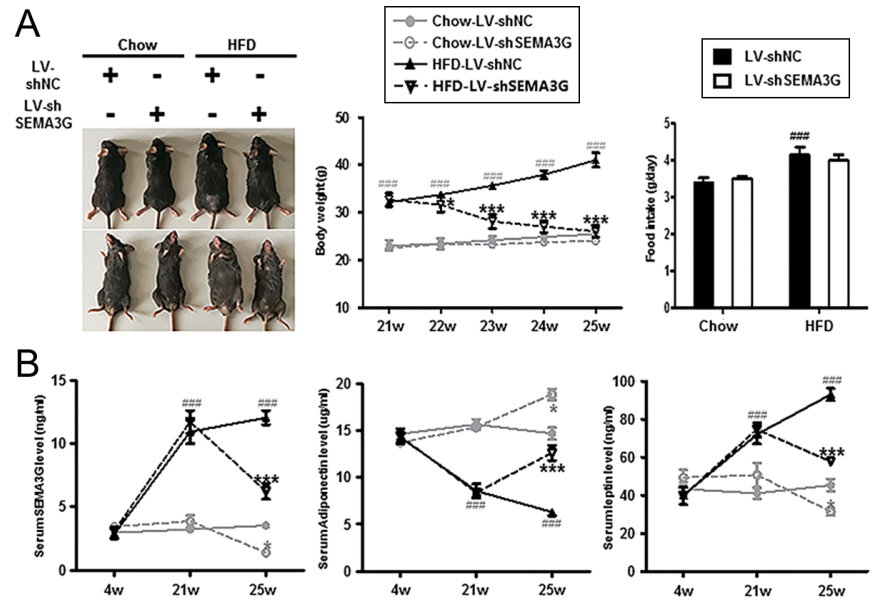

C
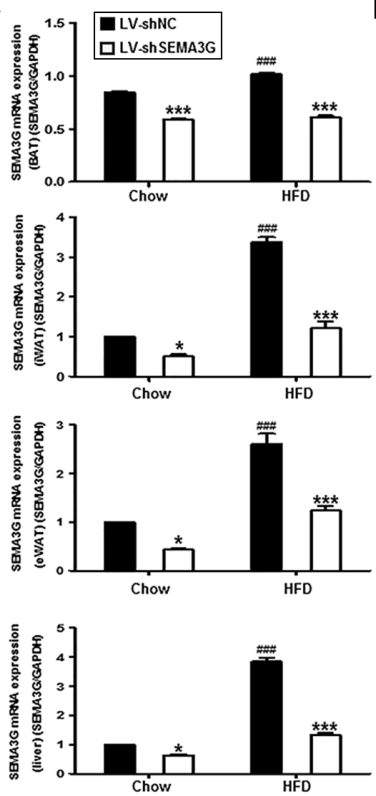
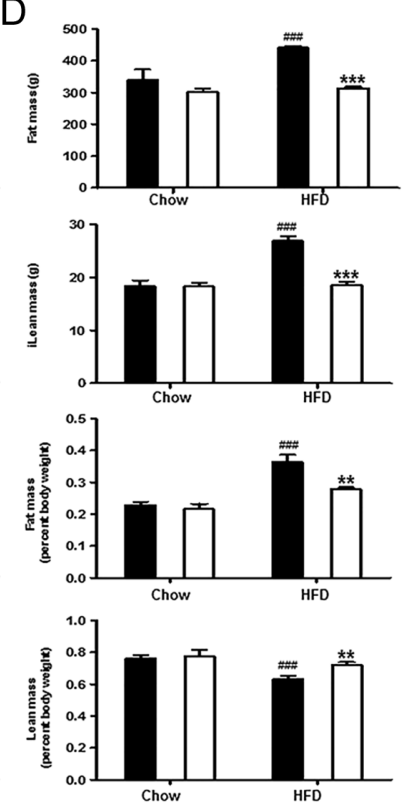

Figure 3

Effect of SEMA3G knockdown on SEMA3G, adiponectin, and leptin levels in chow diet- and HFD-fed mice (A). Body weight and food intake after administration of four different diets for 4 weeks ( $n=6$ mice per group). (B) Changes in SEMA3G, adiponectin, and leptin levels in serum before and after injection of LV-shSEMA3G after 21 weeks of administration of four different diets ( $n=6$ mice per group). (C) SEMA3G mRNA expression in BAT, iWAT, eWAT, and liver of the four groups of mice ( $n=6$ mice per group). (D) Fat mass and lean mass changes and the mass plotted as a percentage of total body weight of the four groups of mice ( $n=6$ mice per group). Data are expressed as mean \pm S.D. ${ }^{*} P<0.05 ; * \star P<0.01 ; * \star \star * P<0.001$ vs HFD-LV-shNC. $\# \#<0.01$; $\# \# P<0.001$ vs chow-LV-shNC. A full colour version of this figure is available at https://doi.org/10.1530/JOE-19-0029.

free tissue accumulation. Additionally, when expressed as a percentage of total body weight, lean mass of the HFD-LV-shNC mice was significantly lower than the other three groups due to the large increase in fat mass (Fig. 3D). These data suggested that SEMA3G knockdown may antagonize the changes in serum levels of adiponectin and leptin, and alleviate obesity induced by HFD.

\section{SEMA3G knockdown ameliorated insulin resistance in HFD-fed mice and altered white adipocyte size and liver lipid deposition}

In order to determine the impact of SEMA3G on glucose homeostasis, we performed glucose (GTT) and insulin (ITT) tolerance tests on the four groups of mice at week 25 , each group contains six mice and half males and half females. HFD mice exhibited impaired glucose tolerance and insulin resistance compared to chow-diet mice. Notably, in LV-shSEMA3G-injected HFD mice, glucose tolerance improved significantly, and insulin sensitivity was almost normalized (Fig. 4A). GTT areas under the curve (AUC) decreased by 30\% in chow-LV-shSEMA3G mice compared to chow-LV-shNC mice, increased by $50 \%$ in HFD-LV-shNC compared with chow-LV-shNC, while ITT AUC decreased by $20 \%$ and increased by $30 \%$ respectively in these groups above. GTT and ITT AUC decreased by $40 \%$, respectively, in HFD-LV-shSEMA3G mice compared to HFD-LV-shNC mice (Fig. 4B). At week 25, HFD mice displayed a significantly higher triglyceride (TG) level compared to chow mice. However, after LV-shSEMA3G treatment, TG level in HFD mice decreased by 50\% compared to HFD-LV-shNC and was close to the normal level typical of chow-diet mice. Total cholesterol (TC) levels showed no significant alterations in the four groups (Fig. 4C). In the HFD-LV-shNC mice, hematoxylin and eosin staining showed significantly enlarged adipocytes, as compared to those of chow-LV-shNC animals. The size of adipocytes decreased in HFD-LV-shSEMA3G mice compared to HFD-LV-shNC mice (Fig. 4D). Image $\mathrm{J}$ software was used to determine the exact size of adipocytes in an average number of 20 cells per section. The diameter of adipocytes was increased $(199.4 \pm 19.2 \mu \mathrm{m})$ in HFD-LV-shNC mice compared to chow-diet with and without shSEMA3G mice (127.1 \pm 9.2 $\mu \mathrm{m}, 114.5 \pm 8.5 \mu \mathrm{m})$. However, the diameter of adipocytes was decreased to $165.8 \pm 13.5 \mu \mathrm{m}$ in HFD-LV-shSEMA3G mice (Fig. 4E). To evaluate fat accumulation in liver, oil red $\mathrm{O}$ was employed to stain the 
A $\rightarrow-$ Chow.LV.ShNC $-\Theta \cdot$ Chow.LV.ShSEMA3G

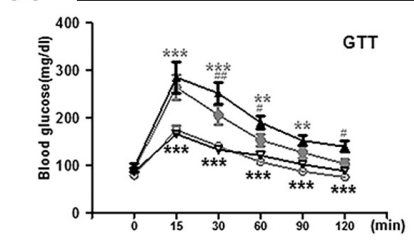

B
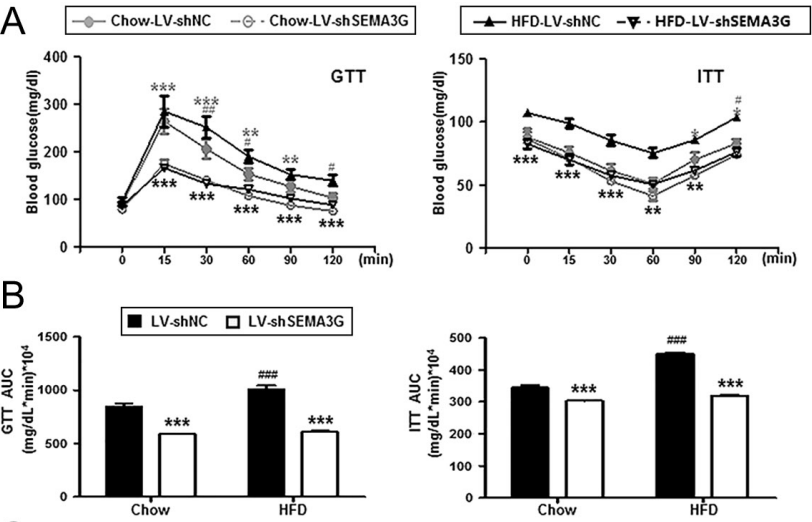

C

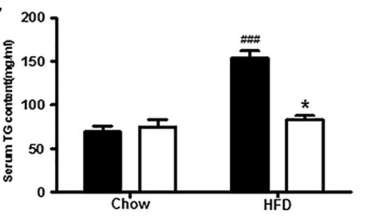

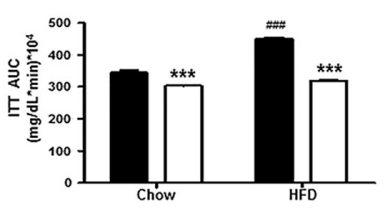

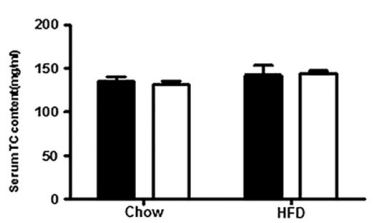

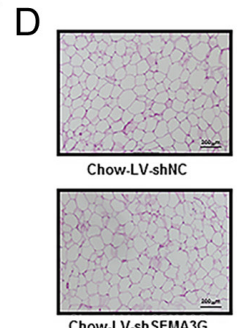

F

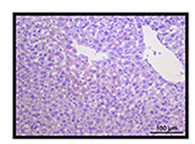

Chow.LV.shNC

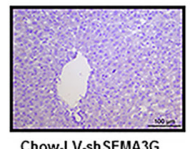

Chow.LV-ShSEMA3G
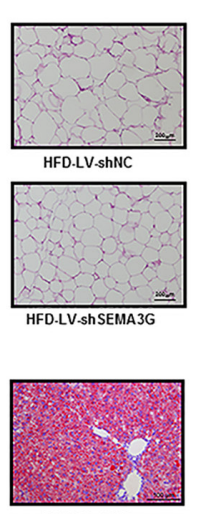

HFD.LV.ShNC

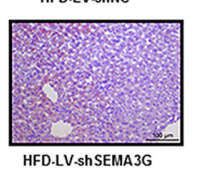

$E$

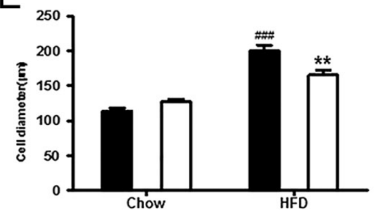

G
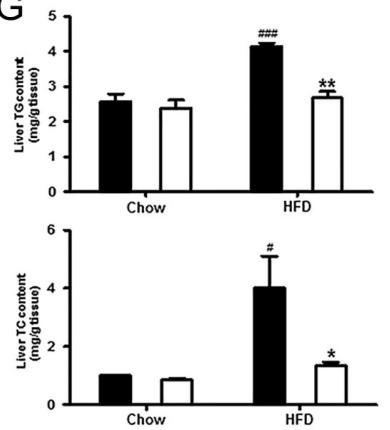

\section{Figure 4}

Effects of SEMA3G knockdown on glucose and insulin tolerance in chow diet- and HFD-fed mice (A). Glucose tolerance test (GTT) and insulin tolerance test (ITT) curve in the four groups of mice after intraperitoneal administration of glucose and insulin. Glucose and insulin were administered per total body mass at $1 \mathrm{~g} / \mathrm{kg}$ and $1 \mathrm{U} / \mathrm{kg}$, respectively ( $n=6$ mice per group). (B) GTT and ITT AUC in the four groups. (C) Serum triglyceride and cholesterol content of four groups. (D) Hematoxylin and eosin staining of liver sections in the four groups (200x). (E) Diameter of adipocytes. (F) Photographs of representative liver sections after oil red O staining of four groups (200x). (G) Liver triglyceride and cholesterol content. Data are expressed as mean \pm s.D. $\star \star \star P<0.001$ vs chow-LV-shNC. $* P<0.05 ; * \star P<0.01 ; * \star * P<0.001$ vs HFD-LV-shNC. $\# P<0.05 ; \# \# P<0.001$ vs chow-LV-shNC. A full colour version of this figure is available at https://doi.org/10.1530/JOE-19-0029.

liver sections of the four groups of animals. Fatty droplets were clearly detected in liver sections from HFD-LV-shNC mice. Chow diet mice presented normal droplets, but highfat diet induced large droplets, then SEMA3G knockdown diminished the fat accumulation in the liver (Fig. 4F). In order to determine the lipid deposition, we measured the contents of TG and total cholesterol (TC) in the liver and found that in the HFD-LV-shNC mice they were increased by 1.6- and 4-folds, respectively, compared to chow-LV-shNC mice, while in HFD-LV-shSEMA3G animals, both TG and TC were decreased to levels similar to those of chow-diet mice (Fig. 4G). This suggested that the lipid deposition induced by HFD was specifically caused by liver anabolism.

\section{SEMA3G regulated adipocyte formation via the PI3K/Akt/GSK3 $\beta$ pathway}

We first constructed a lentiviral overexpression vector of SEMA3G, the ELISA results of SEMA3G secretory level in the plasma also confirmed that SEMA3G was overexpressed in mice. Overexpression of SEMA3G promoted obesity and insulin resistance according to body weight, magnetic resonance, and AUC (Supplementary Fig. 3).
Furthermore, we addressed the relationship between the Akt pathway and insulin regulation during adipocyte formation. Western blot analysis showed a substantial increase of SEMA3G protein in Ad-SEMA3G-infected adipocytes, compared to Ad-GF-infected controls. Moreover, SEMA3G overexpression induced an increase in the levels of phosphorylated PI3K, Akt, and GSK3 $\beta$, indicating a SEMA3G-dependent stimulation of the PI3K/Akt/GSK3 $\beta$ pathway (Supplementary Fig. 1D). In order to investigate the molecular mechanism by which SEMA3G promotes adipocyte formation, we first created a high-insulin (100 nM) environment for 3T3-L1 adipocytes and explored the role of intracellular SEMA3G under these conditions. After LV-shSEMA3G-induced knockdown, the endogenous level of SEMA3G, that of phosphorylated PI3K, Akt, and GSK3 $\beta$, as well as the activity of the above mentioned proteins were significantly decreased compared to LV-shNC mice (Fig. 5A and B). Identical results were obtained with primary mouse adipocytes (Fig. $5 \mathrm{C}$ and $\mathrm{D})$. These data indicated that SEMA3G affected the PI3K/Akt/GSK3 $\beta$ pathway, a crucial pathway for adipocyte differentiation and suggested that suppression of SEMA3G expression exerts a protective role in obesity and interferes with disease-related insulin signaling. 
A

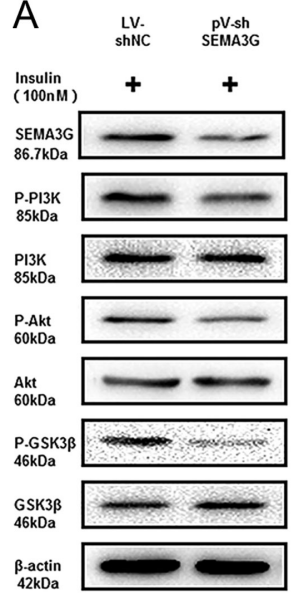

B
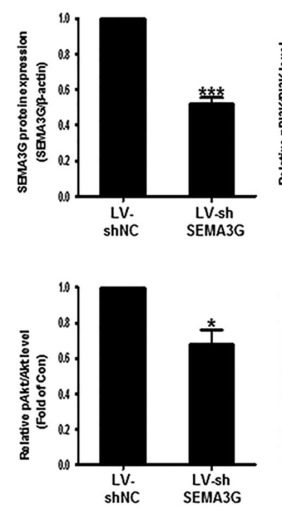
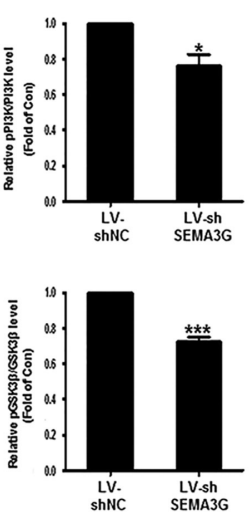

C

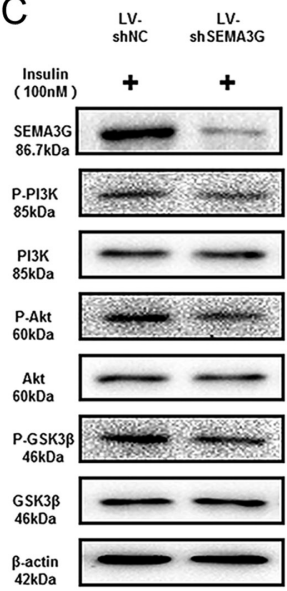

D
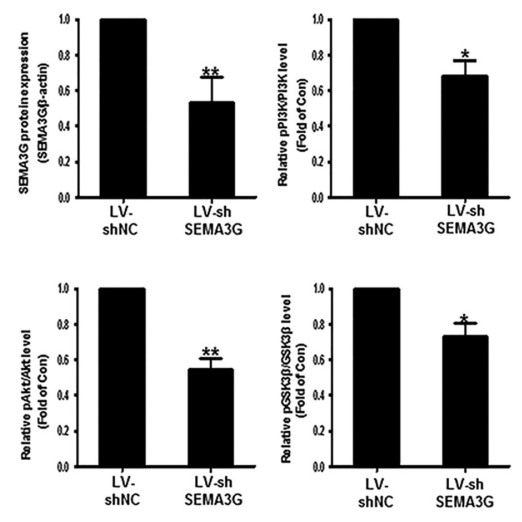

Figure 5

Correlation of the expression of SEMA3G and proteins of the PI3K pathway with adipose differentiation (A). Western blot detection of SEMA3G, P-PI3K, PI3K, P-Akt, Akt, P-GSK3 $\beta$, GSK3 $\beta$ and $\beta$-actin in LV-shNC and LV-shSEMA3G groups in vitro, $n=6$ mice per group. (B) Relative levels of SEMA3G/ $\beta$-actin, P-PI3K/PI3K, P-Akt/Akt, and pGSK3 $\beta / G S K 3 \beta$ in LV-shNC and LV-shSEMA3G groups in vitro, $n=6$ mice per group. (C) Western blot analysis of SEMA3G, P-PI3K, PI3K, P-Akt, Akt, P-GSK3 $\beta$, GSK3 $\beta$, and $\beta$-actin in LV-shNC and LV-shSEMA3G groups in vivo, $n=6$ mice per group. (D) Relative levels of SEMA3G/ $\beta$ actin, P-PI3K/PI3K, P-Akt/Akt, and pGSK3 $\beta / G S K 3 \beta$ in LV-shNC and LV-shSEMA3G groups in vivo, $n=6$ mice per group. Data are expressed as mean \pm s.D. $\star P<0.05 ; * * P<0.01$ vs LV-shNC.

\section{SEMA3G promoted adipogenesis in adipose tissues through the PI3K/Akt/GSK3ß pathway}

To establish the role of SEMA3G in in vivo adipogenesis, we measured the level of SEMA3G and the phosphorylation of PI3K, Akt, and GSK3 $\beta$ in the adipose tissue of the four groups of mice. Western blot showed that SEMA3G protein expression decreased by 50\% in the chow-LV-shSEMA3G mice compared to the chow-LV-shNC mice. On the other hand, in the HFD-LV-shNC group, the levels of SEMA3G and those of phosphorylated PI3K, Akt, and GSK3 $\beta$ were all upregulated compared to the chow-LV-shNC group. Notably, the level of the abovementioned proteins exhibited a 50\% decline after SEMA3G knockdown (Fig. 6A and B). These data suggested that high-fat feeding promotes adipose differentiation through the PI3K/Akt/GSK3 $\beta$ pathway, and that SEMA3G silencing blocks this pathway in the adipose tissue, thus halting the differentiation process.

\section{SEMA3G induced lipogenesis in the liver via the AMPK/SREBP-1C/FAS/ACC pathway}

In order to explore lipogenesis in the liver, we examined the protein levels of SEMA3G, SREBP-1c, and FAS, as well as the phosphorylation level of AMPK and ACC in the four groups of mice. The reduction in SEMA3G level observed in chow-mice after LV-shSEMA3G injection indicated that LV-shSEMA3G could effectively block intracellular SEMA3G expression. We also found the levels of protein expression of SEMA3G, SREBP-1c, FAS and relative pACC/ACCK increased, but the levels of relative pAMPK/AMPK decreased in HFD-LV-shNC group. In HFD-LV-shSEMA3G group, the levels of SEMA3G,
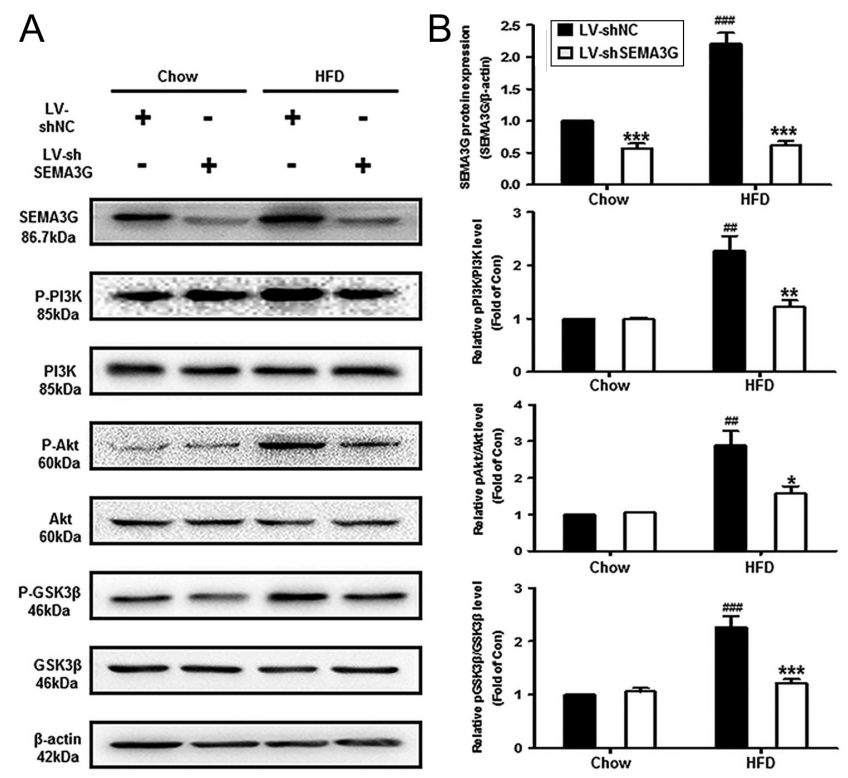

\section{Figure 6}

Effects of SEMA3G knockdown on the levels of proteins of the PI3K pathway in the adipose tissues of chow- and HFD-fed mice (A). Western blot analysis of SEMA3G, P-PI3K, PI3K, P-Akt, Akt, P-GSK3 $\beta$, GSK3 $\beta$, and $\beta$-actin, $n=6$ mice per group. (B) Relative levels of SEMA3G/ $\beta$-actin, P-PI3K/PI3K, P-Akt/Akt, and pGSK3ß/GSK3 $\beta, n=6$ mice per group. Data are expressed as mean \pm s.D. $* P<0.05$; $* * P<0.01$; $* \star * P<0.001$ vs HFD-LV-shNC. \#\#P<0.01; \#\#P<0.001 vs chow-LV-shNC. 
SREBP-1c, FAS, and pACC/ACC were decreased, while pAMPK/AMPK levels were increased, compared to HFD-LV-shNC mice (Fig. 7A and B). These data suggested that high-fat feeding promoted lipogenesis, while SEMA3G knockdown inhibited this process via the AMPK/SREBP-1C/FAS/ACC pathway.

\section{Elevated serum SEMA3G levels in obese human subjects}

The characteristics of participants ( $n=10$ per group) are summarized in Fig. 8A. Body weight (BW) was significantly higher in obese, compared to non-obese, subjects $(P<0.0001)$. Body mass index was also significantly different between the two groups $(P<0.0001)$. The TG level was higher in obese subjects $(1.09 \pm 0.54 \mathrm{mmol} / \mathrm{L}$ for males; $1.28 \pm 0.41 \mathrm{mmol} / \mathrm{L}$ for females) compared to non-obese subjects $(0.75 \pm 0.39 \mathrm{mmol} / \mathrm{L}$ for males; $0.74 \pm$ $0.24 \mathrm{mmol} / \mathrm{L}$ for females; $P=0.0149)$. LDL-C level did not differ between obese and non-obese subjects $(P=0.1146)$. The TC level was significantly higher in obese

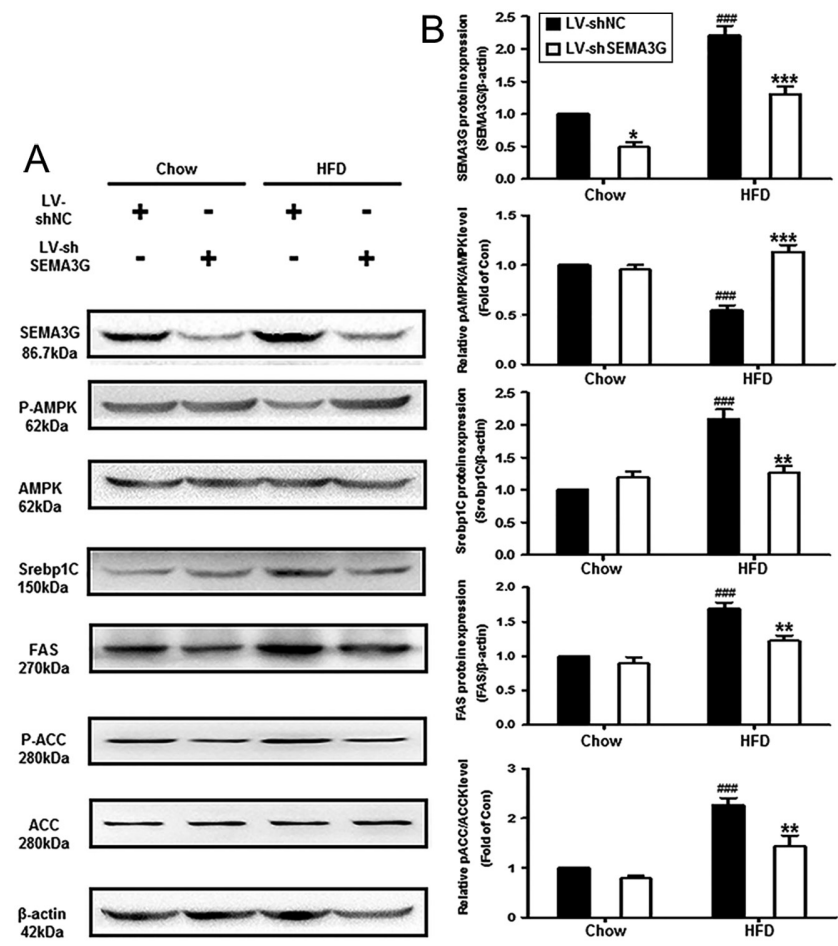

Figure 7

Effects of SEMA3G knockdown on the levels of proteins of the SREBP-1c pathway in the liver of chow- and HFD-fed mice (A). Western blot analysis of SEMA3G, SREBP-1C, P-AMPK, AMPK, P-ACC, ACC, FAS, and $\beta$-actin in the four groups, $n=6$ mice per group. (B) Protein level of SEMA3G and FAS, and relative levels of P-AMPK/AMPK and P-ACC/ACCK in the four groups, $n=6$ mice per group. Data are expressed as mean \pm S.D. $* P<0.05$; $\star \star P<0.01 ; * \star * P<0.001$ vs HFD-LV-shNC. $\# \# P<0.001$ vs chow- LV-shNC.
$(5.81 \pm 1.12 \mathrm{mmol} / \mathrm{L}$ for males; $6.46 \pm 0.81 \mathrm{mmol} / \mathrm{L}$ for females) compared to non-obese subjects $(4.53 \pm 0.69 \mathrm{mmol} / \mathrm{L}$ for males; $4.80 \pm 0.94 \mathrm{mmol} / \mathrm{L}$ for females; $P<0.0001)$. High-density lipoprotein cholesterol (HDL-C) did not significantly differ between obese and non-obese subjects $(P=0.4888)$. Glucose level was significantly higher in obese subjects $(6.59 \pm 1.34 \mathrm{mmol} / \mathrm{L}$ for males; $6.36 \pm 1.11 \mathrm{mmol} / \mathrm{L}$ for

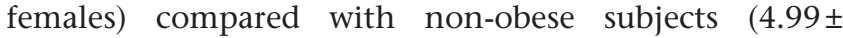
$0.69 \mathrm{mmol} / \mathrm{L}$ for males; $5.59 \pm 0.53 \mathrm{mmol} / \mathrm{L}$ for females). Our results showed that both serum lipids and glucose were significantly increased in obese subjects, independently of sex. We also found that the plasma concentration of SEMA3G in male and female obese subjects was nearly double than that of non-obese subjects. Notably, the plasma concentration of adiponectin exhibited a negative correlation with that of SEMA3G, the increase of leptin level in obese subjects meant explicit leptin resistance (Fig. $8 \mathrm{~B})$. These findings indicated that SEMA3G is elevated in obese subjects.

\section{Discussion}

In this study, we presented the following evidence in support of SEMA3G relevant to obesity. First, we characterized the tissue distribution of SEMA3G in mice. Then, we showed that SEMA3G expression was upregulated during adipose differentiation. Gain- and loss-of-function experiments revealed that SEMA3G is crucial for preadipocyte differentiation. HFD increased body and specific organ weight such as liver and white adipose tissues, altered the serum levels of adiponectin and leptin, increased fasting blood glucose levels, reduced insulin sensitivity, and promoted liver lipogenesis and lipid accumulation. However, shRNA-mediated SEMA3G knockdown reversed the above-mentioned effects, previous studies also used shRNA-mediated SWELL1 knock-down to reduce adiposity and adipocyte size in obese mice while impairing systemic glycemia and insulin sensitivity (Zhang et al. 2017). Further molecular analysis indicated that the SEMA3G-induced effects were mediated by distinct signaling pathways in different tissues. We showed that SEMA3G deficiency blocked the PI3K/Akt/GSK3 $\beta$ pathway in the adipose tissue and the AMPK/SREBP-1c/FAS/ACC pathway in the liver.

In addition to the two classical adipokines, adiponectin and leptin, several other adipokines are known to exist, such as fibroblast growth factor 21, dipeptidyl peptidase 4, vaspin, omentin, and cathepsins 


\begin{tabular}{|c|c|c|c|c|c|c|c|c|c|}
\hline Characteristics & Age(years) & Height(cm) & $B W(\mathrm{~kg})$ & $\mathrm{BMl}\left(\mathbf{k g} / \mathrm{m}^{2}\right)$ & $\mathrm{TG}(\mathrm{mmol} / \mathrm{l})$ & LDL-C(mmollil) & $\mathrm{TC}(\mathrm{mmol} / \mathrm{l})$ & $\mathrm{HDL}-\mathrm{C}(\mathrm{mmol} / \mathrm{l})$ & $\mathrm{GLU}(\mathrm{mmol} / \mathrm{L})$ \\
\hline $\begin{array}{l}\text { Non-obese subjects } \\
\text { (male) }\end{array}$ & $67.3 \pm 5.42$ & $166.1 \pm 2.59$ & $66 \pm 3.82$ & $23.9 \pm 1.15$ & $0.75 \pm 0.39$ & $2.66 \pm 0.83$ & $4.53 \pm 0.69$ & $1.19 \pm 0.30$ & $4.99 \pm 0.69$ \\
\hline $\begin{array}{l}\text { Obese subjects } \\
\text { (male) }\end{array}$ & $70.4 \pm 7.22$ & $168.1 \pm 5.15$ & $84.6 \pm 5.75$ & $29.9 \pm 1.27$ & $1.09 \pm 0.54$ & $3.32 \pm 0.80$ & $5.81 \pm 1.122^{*}$ & $1.32 \pm 0.21$ & $6.59 \pm 1.34{ }^{\prime \prime}$ \\
\hline $\begin{array}{l}\text { Non-obese subjects } \\
\text { (female) }\end{array}$ & $69 \pm 6.77$ & $162 \pm 6.13$ & $63.9 \pm 6.04$ & $24.4 \pm 2.80$ & $0.74 \pm 0.24$ & $3.39 \pm 0.85$ & $4.80 \pm 0.94$ & $1.17 \pm 0.30$ & $5.59 \pm 0.53$ \\
\hline $\begin{array}{l}\text { Obese subjects } \\
\text { (female) }\end{array}$ & $68.2 \pm 5.47$ & $161.3 \pm 7.43$ & $76 \pm 8.50$ & $29.1 \pm 1.13$ & $1.28 \pm 0.41$ & $3.43 \pm 0.65$ & $\frac{m}{6.46 \pm 0.81}$ & $1.28 \pm 0.20$ & $6.36 \pm 1.11$ \\
\hline
\end{tabular}

\title{
B
}
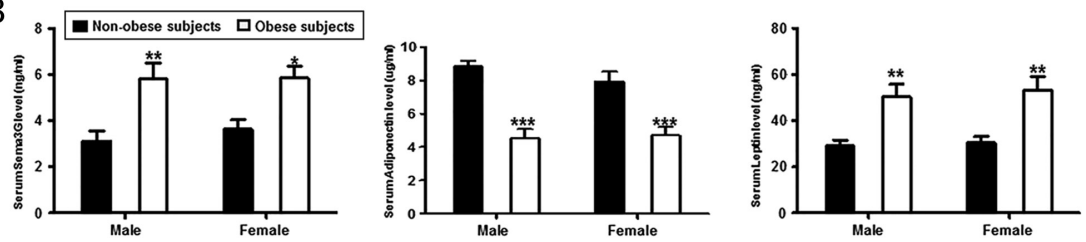

\begin{abstract}
Figure 8
Details of human subjects (A). Characteristics of participants. (B) Serum level of SEMA3G, adiponectin, and leptin. Data are expressed as mean \pm S.D. $* P<0.05 ; * \star P<0.01 ; * \star \star P<<0.001$.
\end{abstract}

(Fasshauer \& Bluher 2015). We focused here, on a member of the SEMA3 family of secretory adipokines and extensively studied its functions. Unlike other semaphorins, SEMA3 dimers bind to Nrp dimers with plexins on each side and, together, they form a complex (Nasarre et al. 2014). Here are some examples describing the functions of SEMA3s. SEMA3A and Nrp1 are detected in the white adipose tissues (Nasarre et al. 2014). They might promote the osteogenesis ability of the adiposederived stem cells (ASCs) and, therefore, serve as targets to facilitate osseointegration in T2DM (Fang et al. 2016). SEMA3C is associated with weight changes; its secretion is involved in extracellular matrix (ECM) construction and may result in pathophysiological effects in human WAT (Mejhert et al. 2013). The SEMA3E-plexin D1 axis, upregulated by p53 in the adipose tissue, was reported to promote macrophage infiltration and induce inflammation and insulin resistance in dietary obesity (Shimizu et al. 2013). SEMA7A was demonstrated to be associated with adipocyte differentiation (Xu et al. 2017). The plexin-4/semaphorin-6a axis in the macrophage crosstalk could impair sympathetic innervation of BAT and alter body composition, thereby leading to obesity (Wolf et al. 2017). By inducing the endothelial deletion of Nrp1 and FLT1 receptor genes, signaling through VEGFR2 and VEGF-A bioavailability can be activated, promoting lacteal junction zippering, inhibiting chylomicron uptake, and ultimately protecting against dietary obesity (Feng et al. 2018). Our results showed that SEMA3G was secreted from adipocytes and could be detected in the supernatant and plasma; moreover, its variations were paralleled by changes in the levels of adiponectin and leptin. When Nrp2, the receptor of SEMA3G in the adipocytes, was suppressed in the experiment, the related downstream pathway was blocked, thereby preventing

(c) 2020 Society for Endocrinology Published by Bioscientifica Ltd. Printed in Great Britain adipogenesis. Consequently, SEMA3G can be considered as a novel adipokine.

The PI3K/Akt/GSK3 $\beta$ pathway has attracted considerable attention owing to its metabolic effects. SEMA3A, SEMA3B, and SEMA3F have been reported to reduce the level of phosphorylated Akt in different cell types. Other reports showed that Akt phosphorylation induced by SEMA3D in HUVECs requires PI3K signaling for endothelial repulsion (Aghajanian et al. 2014). Moreover, SEMA4D stimulates the PI3K-Akt pathway in endothelial cells and this activation is essential for endothelial cell chemotaxis (Basile et al. 2005). In activated macrophages, SEMA4A triggers the endothelial PI3K/Akt signal transduction pathway, promoting angiogenesis, and participates in macrophage recruitment and activation in inflammatory injuries (Meda et al. 2012). SEMA5A promotes invasion and metastasis of gastric cancer through the PI3K/Akt/uPA pathway (Pan et al. 2013). In fact, PI3K/Akt is widely recognized as an important pathway in various metabolic processes. Our data clearly provide a different perspective on the role of SEMA3G in adipogenesis. The results support the finding that the absence and presence of SEMA3G displayed opposite effects on regulation of adipocyte differentiation. Taken together, SEMA3G exerts its functions via the PI3K/Akt/GSK3 $\beta$ pathway in the adipose tissue.

Interestingly, the newly characterized AMPK/SREBP-1c axis, may be important for SEMA3G function. Of note, AMPK exerts a pivotal function in lipid metabolism. It has been found that the AMPK activator, AICAR, reduces the cell lifespan but promotes 5-FU-induced apoptosis in gastric cancer cells by increasing SEMA3F, thereby activating AMPK (Wu et al. 2016). The combination of honokiol and magnolol (HM) blunts hepatic steatosis and SREBP-1cmediated hepatic lipogenesis, which may be triggered by AMPK phosphorylation and ACC (Lee et al. 2015). 
AZF zinc finger 1 (JAZF1) activates AMPK but decreases SREBP-1c expression, thereby preventing age- and nutritionrelated hepatic steatosis. PAS kinase stimulates lipogenesis via SREBP-1c in the liver (Wu et al. 2014). Our results present an example of SEMA3G-mediated lipogenesis requiring the AMPK/SREBP-1c signaling pathway in the liver. We here provided insights into the mechanisms by which SEMA3G loss- and gain-of-function affect the levels of AMPK and SREBP-1c, supporting their relevance as novel candidate pharmacological targets. In our experiment, both results of PCR and Western blot in the adipose and liver, and ELISA in the serum, demonstrated that SEMA3G exists in the adipose and liver, and its content could change by knockdown it. Moreover, its content alters and it has specific role in other organs, such as in the brain, one paper reported that selective knockout of SEMA3G in endothelial cells impaired nervous system (Tan et al. 2019). Then to be more rigorous, we will construct the lentivirus that specifically knockdown SEMA3G in adipose tissue and liver to further explore its role.

In conclusion, SEMA3G is a novel adipokine that regulates the differentiation of preadipocytes via distinct pathways in various tissues, which all ultimately lead to obesity promotion. We, therefore, propose SEMA3G as a therapeutic target in obesity and diabetes.

\section{Supplementary materials}

This is linked to the online version of the paper at https://doi.org/10.1530/ JOE-19-0029.

\section{Declaration of interest}

The authors declare that there is no conflict of interest that could be perceived as prejudicing the impartiality of the research reported.

\section{Funding}

This work was supported by grants from the National Science Foundation of China (81270951) and the interdisciplinary medicine Seed Fund of Peking University (BMU2017MX003).

\section{Acknowledgement}

The authors thank Dr Hui Xiong for providing useful suggestions concerning the manuscript.

\section{References}

Aghajanian H, Choi C, Ho VC, Gupta M, Singh MK \& Epstein JA 2014 Sema3d and Sema3e direct endothelial motility through distinct molecular signaling pathways. Journal of Biological Chemistry $\mathbf{2 8 9}$ 17971-17979.

Andrikopoulos S, Blair AR, Deluca N, Fam BC \& Proietto J 2008 Evaluating the glucose tolerance test in mice. American Journal of

(c) 2020 Society for Endocrinology Published by Bioscientifica Ltd. Printed in Great Britain
Physiology: Endocrinology and Metabolism 295 E1323-E1332. (https:// doi.org/10.1152/ajpendo.90617.2008)

Basile JR, Afkhami T \& Gutkind JS 2005 Semaphorin 4D/plexin-B1 induces endothelial cell migration through the activation of PYK2, Src, and the phosphatidylinositol 3-kinase-Akt pathway. Molecular and Cellular Biology 25 6889-6898. (https://doi.org/10.1128/MCB.25.16.6889-6898.2005)

Binxia Y, Rajiv J, Pawan V, Greene EL, Santanu B, Sarah W, Bhaskar R, Torres EC, Mandrekar J, Leof EB, et al. 2014 Adventitial transduction of lentivirus-shRNA-VEGF-A in arteriovenous fistula reduces venous stenosis formation. Kidney International 85 289-306. (https://doi. org/10.1038/ki.2013.290)

Bussolino F, Giraudo E \& Serini G 2014 Class 3 semaphorin in angiogenesis and lymphangiogenesis. Chemical Immunology and Allergy 99 71-88. (https://doi.org/10.1159/000353315)

Cabia B, Andrade S, Carreira MC, Casanueva FF \& Crujeiras AB 2016 A role for novel adipose tissue-secreted factors in obesity-related carcinogenesis. Obesity Reviews 17 361-376. (https://doi.org/10.1111/obr.12377)

Dihingia A, Bordoloi J, Dutta P, Kalita J \& Manna P 2018 Hexaneisopropanolic extract of tungrymbai, a north-east Indian fermented soybean food prevents hepatic steatosis via regulating AMPK-mediated SREBP/FAS/ACC/HMGCR and PPAR $\alpha / C P T 1 A / U C P 2$ pathways. Scientific Reports 8 10021. (https://doi.org/10.1038/s41598-018-27607-7)

Fang K, Song W, Wang L, Xu X, Tan N, Zhang S, Wei H \& Song Y 2016 Semaphorin 3A-modified adipose-derived stem cell sheet may improve osseointegration in a type 2 diabetes mellitus rat model. Molecular Medicine Reports 14 2449-2456. (https://doi.org/10.3892/ mmr.2016.5568)

Fasshauer M \& Bluher M 2015 Adipokines in health and disease. Trends in Pharmacological Sciences 36 461-470. (https://doi.org/10.1016/j. tips.2015.04.014)

Feng Z, Zarkada G, Han J, Li J, Dubrac A, Ola R, Genet G, Boyé K, Michon P \& Künzel SE 2018 Lacteal junction zippering protects against diet-induced obesity. Science 361 599-603. (https://doi. org/10.1126/science.aap9331)

Fromm-Dornieden C, Heyde SVD, Lytovchenko O, Salinas-Riester G, Brenig B, Beissbarth T \& Baumgartner BG 2012 Novel polysome messages and changes in translational activity appear after induction of adipogenesis in 3T3-L1 cells. BMC Molecular Biology 13 9. (https:// doi.org/10.1186/1471-2199-13-9)

Giralt M \& Villarroya F 2013 White, brown, beige/brite: different adipose cells for different functions? Endocrinology 154 2992-3000. (https:// doi.org/10.1210/en.2013-1403)

Gregg EW \& Shaw JE 2017 Global health effects of overweight and obesity. New England Journal of Medicine 377 80-81. (https://doi. org/10.1056/NEJMe1706095)

Ishibashi R, Takemoto M, Akimoto Y, Ishikawa T, He P, Maezawa Y, Sakamoto K, Tsurutani Y, Ide S, Ide K, et al. 2016 A novel podocyte gene, semaphorin $3 \mathrm{G}$, protects glomerular podocyte from lipopolysaccharide-induced inflammation. Scientific Reports 625955. (https://doi.org/10.1038/srep25955)

Ito T, Kagoshima M, Sasaki Y, Li C, Udaka N, Kitsukawa T, Fujisawa H, Taniguchi M, Yagi T, Kitamura H, et al. 2000 Repulsive axon guidance molecule Sema3A inhibits branching morphogenesis of fetal mouse lung. Mechanisms of Development 97 35-45. (https://doi.org/10.1016/ s0925-4773(00)00401-9)

Kadowaki T, Yamauchi T, Kubota N, Hara K, Ueki K \& Tobe K 2006 Adiponectin and adiponectin receptors in insulin resistance, diabetes, and the metabolic syndrome. Journal of Clinical Investigation $\mathbf{1 1 6}$ 1784-1792. (https://doi.org/10.1172/JCI29126)

Kagoshima M \& Ito T 2001 Diverse gene expression and function of semaphorins in developing lung: positive and negative regulatory roles of semaphorins in lung branching morphogenesis. Genes to Cells 6 559-571. (https://doi.org/10.1046/j.1365-2443.2001.00441.x)

Khemka V \& Banerjee A 2017 Metabolic risk factors in obesity and diabetes mellitus: implications in the pathogenesis and therapy. Integrative Obesity and Diabetes 3 2-4. (https://doi.org/10.15761/ IOD.1000179) 
Kuri-Harcuch W, Velez-delValle C, Vazquez-Sandoval A, Hernández Mosqueira C \& Fernandez-Sanchez V 2019 A cellular perspective of adipogenesis transcriptional regulation. Journal of Cellular Physiology 234 1111-1129. (https://doi.org/10.1002/jcp.27060)

Kutschera S, Weber H, Weick A, de Genove SF, Takemoto G, Prahst M, Riedel C, Mikelis C, Baulande S, et al. 2010 Differential endothelial transcriptomics identifies semaphorin $3 \mathrm{G}$ as a vascular class 3 semaphorin. Arteriosclerosis, Thrombosis and Vascular Biology 31 151-159. (https://doi.org/10.1161/ATVBAHA.110.215871)

Lee JH, Jung JY, Jang EJ, Jegal KH, Moon SY, Ku SK, Kang SH, Cho IJ, Park SJ, Lee JR, et al. 2015 Combination of honokiol and magnolol inhibits hepatic steatosis through AMPK-SREBP-1c pathway. Experimental Biology and Medicine 240 508-518. (https://doi. org/10.1177/1535370214547123)

Lefterova MI, Haakonsson AK, Lazar MA \& Mandrup S 2014 PPAR $\gamma$ and the global map of adipogenesis and beyond. Trends in Endocrinology and Metabolism 25 293-302. (https://doi.org/10.1016/j.tem.2014.04.001)

Li YC, Qiao JY, Wang BY, Bai M, Shen JD \& Cheng YX 2018 Paeoniflorin ameliorates fructose-induced insulin resistance and hepatic steatosis by activating LKB1/AMPK and Akt pathways. Nutrients 101024. (https://doi.org/10.3390/nu10081024)

Liu W, Li J, Liu M, Zhang H \& Wang N 2015 PPAR- $\gamma$ promotes endothelial cell migration by inducing the expression of Sema3g. Journal of Cellular Biochemistry 116 514-523. (https://doi.org/10.1002/jcb.24994)

Liu XJ, Wu XY, Wang H, Wang SX, Kong W, Zhang L, Liu G \& Huang W 2018 Renal injury in seipin-deficient lipodystrophic mice and its reversal by adipose tissue transplantation or leptin administration alone: adipose tissue-kidney crosstalk. FASEB Journal 32 5550-5562. (https://doi.org/10.1096/fj.201701427R)

Marta G \& Francesc V 2013 White, brown, beige/brite: different adipose cells for different functions? Endocrinology 154 2992-3000. (https:// doi.org/10.1210/en.2013-1403)

Meda C, Molla F, De Pizzol M, Regano D, Maione F, Capano S, Locati M, Mantovani A, Latini R, Bussolino F, et al. 2012 Semaphorin 4A exerts a proangiogenic effect by enhancing vascular endothelial growth factor-A expression in macrophages. Journal of Immunology 188 4081-4092. (https://doi.org/10.4049/jimmunol.1101435)

Mejhert N, Wilfling F, Esteve D, Galitzky J, Pellegrinelli V, Kolditz CI, Viguerie N, Tordjman J, Näslund E, Trayhurn P, et al. 2013 Semaphorin 3C is a novel adipokine linked to extracellular matrix composition. Diabetologia 56 1792-1801. (https://doi.org/10.1007/ s00125-013-2931-z)

Musso G, Paschetta E, Gambino R, Cassader M \& Molinaro F 2013 Interactions among bone, liver, and adipose tissue predisposing to diabesity and fatty liver. Trends in Molecular Medicine 19 522-535. (https://doi.org/10.1016/j.molmed.2013.05.006)

Nasarre P, Gemmill RM \& Drabkin HA 2014 The emerging role of class-3 semaphorins and their neuropilin receptors in oncology. OncoTargets and Therapy 7 1663-1687. (https://doi.org/10.2147/OTT.S37744)

Ok E, Do GM, Lim Y, Park JE, Park YJ \& Kwon O 2013 Pomegranate vinegar attenuates adiposity in obese rats through coordinated control of AMPK signaling in the liver and adipose tissue. Lipids in Health and Disease 12 163-163. (https://doi.org/10.1186/1476-511X-12-163)

Pan G, Zhu Z, Huang J, Yang C, Yang Y, Wang Y, Tuo X, Su G, Zhang X, Yang Z, et al. 2013 Semaphorin 5A promotes gastric cancer invasion/metastasis via urokinase-type plasminogen activator/ phosphoinositide 3-kinase/protein kinase B. Digestive Diseases and Sciences 58 2197-2204. (https://doi.org/10.1007/s10620-013-2666-1)

Pasterkamp RJ 2012 Getting neural circuits into shape with semaphorins. Nature Reviews: Neuroscience 13 605-618. (https://doi.org/10.1038/ nrn3302)
Poulos S, Dodson \& Hausman G 2010 Cell line models of preadipocytes and adipocytes. Bulletin of Experimental Biology and Medicine 235 1185-1193. (https://doi.org/10.1258/ebm.2010.010063)

Rosenbaum M \& Leibel RL 2014 Role of leptin in energy homeostasis in humans. Journal of Endocrinology 223 T83-T96. (https://doi. org/10.1530/JOE-14-0358)

Sarjeant K \& Stephens JM 2012 Adipogenesis. Cold Spring Harbor Perspectives in Biology 4 a008417. (https://doi.org/10.1101/cshperspect.a008417)

Schultze SM, Hemmings BA, Niessen M \& Tschopp O 2012 PI3K/AKT, MAPK and AMPK signalling: protein kinases in glucose homeostasis. Expert Reviews in Molecular Medicine 14 e1. (https://doi.org/10.1017/ S1462399411002109)

Serini G, Bussolino F, Maione F \& Giraudo E 2013 Class 3 Semaphorins: physiological vascular normalizing agents for anti-cancer therapy. Journal of Internal Medicine 273 138-155. (https://doi.org/10.1111/joim.12017)

Shimizu I, Yoshida Y, Moriya J, Nojima A, Uemura A, Kobayashi Y \& Minamino T 2013 Semaphorin3E-induced inflammation contributes to insulin resistance in dietary obesity. Cell Metabolism 18 491-504. (https://doi.org/10.1016/j.cmet.2013.09.001)

Tan C, Lu NN, Wang CK, Chen DY, Sun NH, Lyu H, Körbelin J, Shi WX, Fukunaga K, Lu YM, et al. 2019 Endothelium-derived semaphorin $3 \mathrm{G}$ regulates hippocampal synaptic structure and plasticity via Neuropilin-2/PlexinA4. Neuron 101 920.e13-937.e13. (https://doi. org/10.1016/j.neuron.2018.12.036)

Taniguchi M, Masuda T, Fukaya M, Kataoka H, Mishina M, Yaginuma H, Watanabe M \& Shimizu T 2005 Identification and characterization of a novel member of murine semaphorin family. Genes to Cells $\mathbf{1 0}$ 785-792. (https://doi.org/10.1111/j.1365-2443.2005.00877.x)

Valdembri D, Regano D, Maione F, Giraudo E \& Serini G 2016 Class 3 semaphorins in cardiovascular development. Cell Adhesion and Migration 10 641-651. (https://doi.org/10.1080/19336918.2016.1212805)

Vallée A, Lecarpentier Y, Guillevin R \& Vallée JN 2017 Interactions between TGF- $\beta 1$, canonical WNT/ $\beta$-catenin pathway and PPAR $\gamma$ in radiation-induced fibrosis. Oncotarget 8 90579-90604. (https://doi. org/10.18632/oncotarget.21234)

Wang K, Tang Z, Zheng Z, Cao P, Shui W, Li Q \& Zhang Y 2016 Protective effects of Angelica sinensis polysaccharide against hyperglycemia and liver injury in multiple low-dose streptozotocin-induced type 2 diabetic BALB/c mice. Food and Function 7 4889-4897. (https://doi. org/10.1039/c6fo01196a)

Wolf Y, Bourahalfon S, Cortese N, Haimon Z, Shalom HS, Kuperman Y, Kalchenko V, Brandis A, David E, Segalhayoun Y, et al. 2017 Brown-adipose-tissue macrophages control tissue innervation and homeostatic energy expenditure. Nature Immunology 18 665-674. (https://doi.org/10.1038/ni.3746)

Wu X, Romero D, Swiatek WI, Dorweiler I, Kikani CK, Sabic H, Zweifel BS, Mckearn J, Blitzer JT, Nickols GA, et al. 2014 PAS kinase drives lipogenesis through SREBP-1 maturation. Cell Reports 8 242-255. (https://doi.org/10.1016/j.celrep.2014.06.006)

Wu Y, Qi Y, Liu H, Wang X, Zhu H \& Wang Z 2016 AMPK activator AICAR promotes 5-FU-induced apoptosis in gastric cancer cells. Molecular and Cellular Biochemistry 411 299-305. (https://doi.org/10.1007/s11010015-2592-y)

Xu X, Jiang H, Li X, Wu P, Liu J, Wang T, Zhou X, Xiong J \& Li W 2017 Bioinformatics analysis on the differentiation of bone mesenchymal stem cells into osteoblasts and adipocytes. Molecular Medicine Reports 15 1571-1576. (https://doi.org/10.3892/mmr.2017.6178)

Zhang Y, Xie L, Gunasekar SK, Tong D, Mishra A, Gibson WJ, Wang C, Fidler T, Marthaler B, Klingelhutz A, et al. 2017 SWELL1 is a regulator of adipocyte size, insulin signalling and glucose homeostasis. Nature Cell Biology 19 504-517. (https://doi.org/10.1038/ncb3514)

Received in final form 16 October 2019

Accepted 24 October 2019

Accepted Manuscript published online 24 October 2019 https://joe.bioscientifica.com https://doi.org/10.1530/JOE-19-0029 (c) 2020 Society for Endocrinology Published by Bioscientifica Ltd. Printed in Great Britain 